\title{
Get Gamification of MOOC right!
}

\section{How to Embed the Individual and Social Aspects of MOOCs in Gamification Design.}

\author{
Alessandra Antonaci ${ }^{1}$, Roland Klemke ${ }^{1}$, Karel Kreijns ${ }^{1}$, Marcus Specht ${ }^{1}$ \\ ${ }^{l}$ Welten Institute, Open University of the Netherlands, Heerlen, Netherlands, \\ alessandra.antonaci@ou.nl
}

\begin{abstract}
The social and individual aspects of MOOCs are two sides of the same coin. However, while the majority of MOOC designs do not valorise the potential that a massive audience could bring in, several studies highlight the solomission mode of MOOC users' experience. Based on implementation intention, social presence, social influence and flow theory we conceptualise our gamification design of MOOCs that embraces their social and individual aspects. We present the gamification design process, our theoretical framework, the quantitative and qualitative results of our study to identify the most suitable game elements, their conceptual design, and our recommendations. Our findings enable designers of gamification and MOOCs as well, to see these two phenomena under a new light, by referring to new theories and new game elements that were not being considered before in the design of a gamified MOOC aiming at enhancing users' goal achievement and engagement.
\end{abstract}

Keywords: MOOC, Gamification, Process, Design, Social Gamification, Learner Characteristics, Social Presence, Persuasion, Flow

\section{Introduction}

Designing gamification is not a linear process. Gamification is a transversal discipline and the design of gamified interventions embraces its complexity.

This complexity is due to the fact that gamification is influenced by several disciplines, such as psychology, learning science and design, game science and design, user experience (UX) design, human-computer-interaction (HCI) and technology enhanced learning (TEL) (when the intervention implies the use of technology) [1]. Knowing so, how does the design of gamification need to be approached?

Let's start with explaining what we mean by gamification: it is the application of elements belonging to games to a non-game scenario [2] with the aim of creating an effect, (for instance solving the problem typical of the application scenario) or generating a change in users' behaviour. This definition highlights that gamification design is relative, it depends on the context, the problem we want to solve, the effects we want to generate, as well as the target audience. Consequently, a single gamification design cannot be suitable for all situations.

Already three years ago in their literature review, [3] reported on eighteen frameworks for design gamification, related to the following fields: economic; logic; measurement; psychology and user interaction [3]. More recently are available gamification design frameworks focused on graphical modelling and the importance of the UX [4]; relative to the design of gamified software engineering [5], [6], or on the gamification of crowdsources systems [7]. 
With this work we aim to contribute to the field by providing a gamification design process and methodology that can be applied in different scenarios, context independent and that therefore is generalizable.

Even though the gamification design is relative, there are general rules applicable, independent of the context. We have conceptualized these in the gamification design cycle (shown here in Figure 1), inspired by the engineering design cycle applied to STEM ${ }^{1}$ education [8].

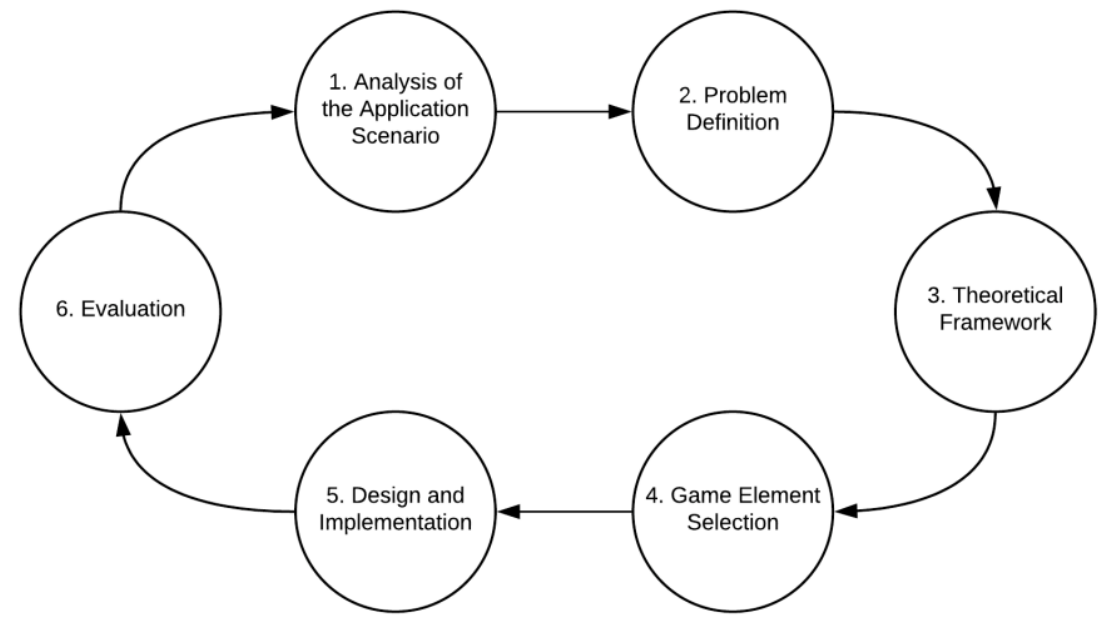

Figure 1. The process of Gamification design

The gamification design process consists of six consecutive phases:

1. Analysis of the application scenario

This phase implies acquiring an overall understanding of the characteristics and features relative to the context in which gamification needs to be employed. Gamification has been implemented in online, face to face and mobile applications, related to several domains such as education [9], [10], software engineering [11], retail [12], marketing [13] and physical activity [14]. However, as specified above, designing an implementation of gamification is related to the scenario and its characteristics. In this work we focus on Massive Online Open Courses (MOOCs), and in the next paragraph the peculiarities of this application scenario are detailed.

2. Problem Definition

"Identifying a research problem consists of specifying an issue to study, developing a justification for studying it [...]" [15] and (if it is needed) designing the tool for solving it and the means to measure the effects of the intervention. A problem can be related to a macro level (i.e. society), meso (i.e. community) or micro (i.e. individual/group) level. Our problems are related to the micro level and more specifically to MOOCs.

3. Theoretical framework

As a rule of thumb, the theoretical framework is related to the problem to be solved, and in general, it explains the theories underpinning the study [16]. As [17] showcases, several theories have been adopted in the designing of gamification.

Based on the problem and the scenario of application we refer to four theories as the basis of our theoretical framework: (1) Implementation Intention [18]; (2) Flow

${ }^{1}$ STEM, stands for Science, Technology, Engineering, and Math. 
[19]; (3) Social Presence [20] and (4) Social Influence (persuasion) [21], detailed in paragraph three.

4. Game elements selection

There are a large number of game elements available. Depending on the problems identified in the application field, different gamification approaches have been successful [22]. However, in the literature we have identified a lack of empirical research for gamification applied in our application scenario (MOOCs) and for the purposes we aim to achieve (enhancing MOOC users' goal achievement and engagement). Therefore, we have performed a game element selection based on the problem we aim to solve and our theoretical framework, as explained in paragraph four.

5. Design and implementation

The game elements chosen need to be conceptualised, designed and implemented in a way that suits the purpose of the interventions, the user experience, the application scenario and the logic specified in the theoretical framework. Last but not least, in a MOOC-based scenario the design and implementation of game elements are heavily dependent on the platform used, its features and the level of openness it offers, the budget available and the technical (programming) skills of the gamification designer/s. In this study the focus is on the conceptualisation of the game element selected, paragraph five.

6. Evaluation

The evaluation phase aims to measure the effect of the intervention. Therefore, it can be planned in different steps: pre-evaluation, in itinere (during) and post intervention. As far as the means used is concerned, generally, pre- and postevaluation surveys are often used which can test several factors, such as attitude, perception and UX of gamification design. In itinere, within an online learning scenario an A/B test can be set up, as well as learning analytics, which need to be designed and embedded in the game elements. The results of the evaluation phase can be the start of a new cycle.

The proposed process of gamification design needs to be validated in several fields. To do so the authors have started applying it to a MOOC scenario and structured the paper accordingly: the outline of the state of the art is followed by a brief presentation of the MOOC application scenario (phase one) and the problem definition (phase two), the theoretical framework underpinning of the gamification design of MOOC (phase three), and the game element selection process (phase four). The paper will be concluded with considerations for the design and implementation (phase five) and future work, which is the evaluation (phase six).

\section{Gamification design of MOOC: a summary of the state of the art}

In previous work, the authors [23] have presented several examples of gamified MOOCs underlining the availability of a significant number of conceptual papers and the need for more empirical works.

More specifically, conceptually gamification has been proposed mainly as a solution to enhance motivation and collaboration [24], [25]; to provide personalization and engagement [26], [27] within MOOCs' users and sometime also as a strategy to boost a specific feature of the MOOC, which can for example be videos [28].

From an empirical point of view, what emerges is that gamification has been applied in the same scenario, MOOC, in a largely variegated way. The dissimilarities are due not only to the aim that the gamification design pursued, but mainly to the ways in which designers implement and interpret the game elements. To be more concrete, the collection of game design patterns [29] we refer to is rarely used, authors often prefer to employ more simple game elements, like points, badges, and leaderboards (PBL). For instance, to foster 
page 64

motivation, external rewards and social comparison mechanism are often preferred, mainly in the shapes of badges and leaderboards [30]-[33].

In literature, it is often possible to find works in which the concept of gamification is interpreted and presented as an all, without distinguishing the possible variations among the game elements. The final products of this interpretation are then gamified platforms, which are tested often with an experimental set up that enables to compare the gamified condition with the non- gamified one [34]-[38]. As a consequence of this approach, gamification may be shown as a key factor for the success of a MOOC [39], however, implies for the readers to look only to the general picture, disabling the possibility to zoomin and understand which specific game element is actually effective in that specific condition and which, instead, functions as mediator.

As far as the social and individual aspects of the MOOC scenario are concerned, they are not yet been considered in the designing of gamification for MOOCs. This paper is a contribution in that sense.

The aim of our work is to contribute to the field by giving a different perspective and approach. Our perspective starts from the idea that to apply gamification it is necessary to understand the scenario of application and its peculiarities; therefore, the next session will be dedicated to this aspect.

\section{Analysis of the application scenario: $\mathrm{MOOC}$}

The application scenario considered in this study is MOOC. In designing gamification of MOOCs, we will look at the following five dimensions: (1) individual; (2) social; (3) openness; (4) course design; (5) technology. MOOCs address a massive audience of individuals (learners). Each learner approaching a MOOC brings in different needs, backgrounds, prior knowledge and preferences and in general personal characteristics. More specifically the learner's characteristics, have been widely described in literature and can be summarised in five categories: (1) personal; (2) academic; (3) social; (4) emotional and (5) cognitive [40] (see figure 2).

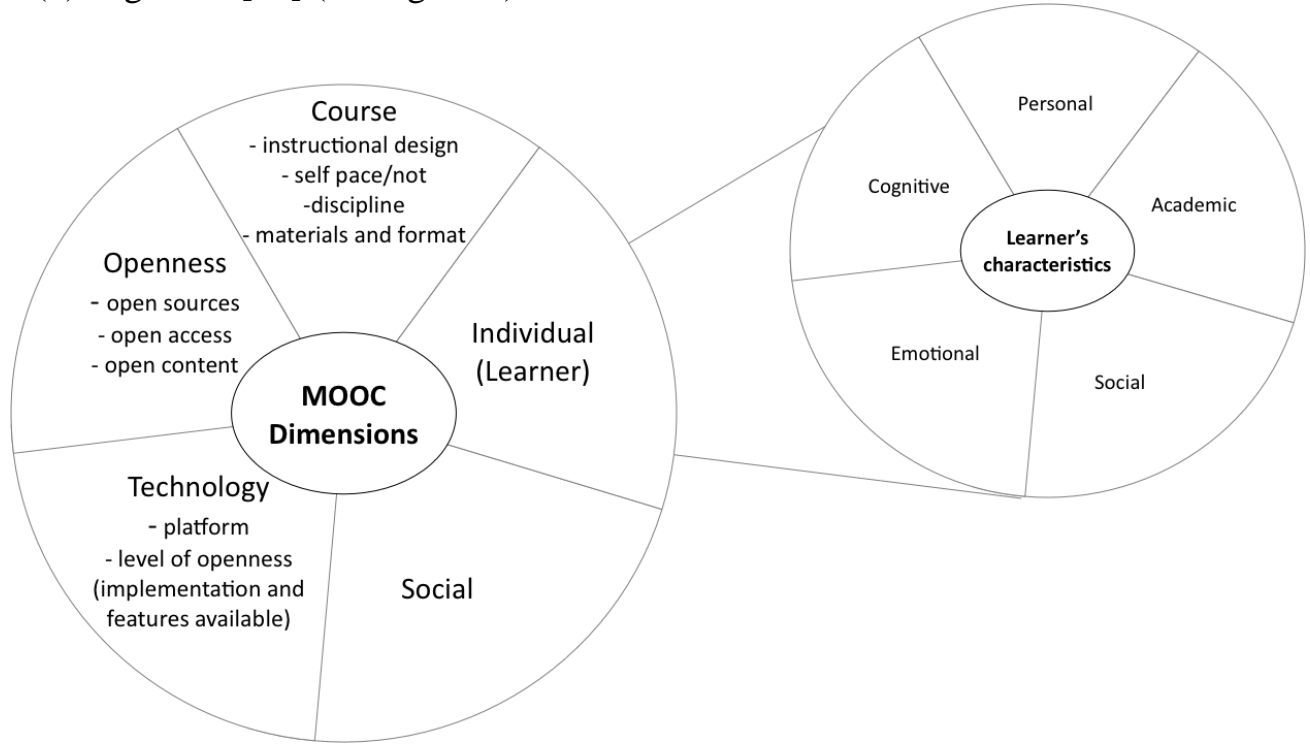

Figure 2. MOOC Dimensions and learner's characteristics

Personal refers to the cultural background, gender, age, in general demographic data, plus the needs of the person, her/his own skills and disabilities (if any), beliefs, orientation, etc. Academic relates to educational background, prior knowledge and learning goals. The social dimension comprises all the dynamics that are stimulated or initiated in a group. The 
emotional dimension can be related to the group but also to the individual. Feelings like self-efficacy, autonomy, self-perception, self-regulation (in relation to yourself and the other), sociability and mood belong to this dimension. Lastly, the cognitive dimension refers to the characteristic each learner has in the way s/he solves problems, organises information in his/her own brain and as well how s/he perceives, remembers, and organises it. Intellectual skills, attention span, memory and mental procedures are part of this dimension.

Learners with their own characteristics share the same environment, where they communicate and interact with each other, therefore there is a social dimension of MOOCs. To acknowledge and consider the potential and the importance of the social dimension of MOOCs is an important step for the design of gamification of MOOCs.

As Vygotsky [41] already pointed out, "the other/s" can be a huge asset for learning, peers can be a scaffold for each other, and enabling users to push forward and increase their zone of proximal development (ZPD) [41]. Several theories such as the social cognitive theory [42], social comparison [43], social influence [44] and social presence [20] have shown how much the social component has an impact on individual behaviours. Some of these theories are at the base of the most often used and effective game elements (i.e. leaderboard, designed and studied in accordance with the social comparison theory [45]). While others are adopted as keys to better understand how games succeed in engaging users; one example is social presence theory that has been used to study Massive Multiplier Online Games (MMOG) to identify the mechanics they implement to successfully engage and retain players [46]. Social presence theory has also been used "to describe and understand how people socially interact in online learning environments" [47]. The understanding and influence of social behaviours online is the principle matter of social influence (persuasion) theory. In the framework of this study these last two theories (social presence and social influence) will be further detailed and connected with our application scenario and problem.

Another highly-discussed dimension of MOOCs is openness. The level of openness of a MOOC platform impacts heavily on the design choice that the gamification designer can make. The level of openness can also influence the design choice. Openness can refer to the technology (the platform per se and to what degree the openness allows designers to build on it, open source or extensibility), the content (open educational recourses) and the cost fee (open access).

Besides, in designing gamification of MOOCs it is important to look at the course or learning design. This refers to the pedagogical approaches adopted in designing the course (i.e. knowledge dissemination, connectivism, project-based learning, case-based learning, collaborative learning or active learning), following for instance a more self-paced approach (cMOOC) or more extended version of the online classical one (xMOOC) [48]; the format used to deliver the content (how they are structured and the format in which they are delivered, for instance mainly videos or exercises); the type of assignments (if any); the level of interaction and collaboration required by means of forum or other tools. Last but not least, the discipline and the content also play a role in the level of interest that can be generated in users, and it is related to the potential designers have to "play" with the content and build up, for instance, a narrative around it as well.

Finally, connected to openness and all the other dimensions is the last one: technology. This relates mainly to the platform adopted (such as: edX, Open edX, Coursera, HPI, canvas, FutureLearn, etc.) and its own course, scoring, social, code features (and level of modifications) that impact on our gamification design.

In figure 2, both the learner's characteristics and the MOOC features and specifications of our application scenario are shown, fundamental characteristics, requirements, that need to be considered in designing gamification of MOOC. 
The MOOC phenomenon has been studied in literature and both its potential and limits have been pointed out. Among the drawbacks, the most recurrent is the low completion rate of MOOCs, which implies a great difference between the number of users that subscribe to a MOOC and the number of learners that actually complete the course and/or earn the certificate [49]. This issue has been addressed in several ways, but from the authors' perspective the concept of completion rate needs to be described and measured in relation to the users and their intention within MOOCs [23]. To be more specific, one of the main problems with MOOCs is that they are treated as traditional courses [50], consequently the success rate of a MOOC is calculated in relation to completion. However, MOOCs are not traditional courses, as explained above they potentially address a massive number of users, who are bearers of an enormous number of needs and characteristics. Therefore, it is very likely that only some of the users who approach a MOOC actually have the intention of completing the course. Our assumption is: if we enable learners to plan their intention within the MOOC, this will enable them to achieve their own goals and consequently the completion rate (considered and measured in relation to users' intentions, therefore as goal achievement) will increase.

Goal achievement is not the only problem we aim to address in MOOCs with our gamification design, we are also interested in the low level of engagement recorded by MOOC users. Looking at the literature, we have found several theories that explain how the level of engagement on individual level (flow) and social level (social influence, social presence) can be enhanced.

Therefore, our assumption is that to increase the level of engagement learners have to develop a sense of community and interdependence with others.

Here below the theories underpinning our gamification design choices are presented in relation to the two problems we identified: (1) difficulty for users to plan and thus to achieve their own goals within MOOCs, (2) lack of engagement.

\subsection{Addressing goal achievement}

Several theories have been used to support users in achieving their own goals such as goal setting theory [51], self-determination theory [52], but the one we found most suitable for MOOC application scenario, and our assumption, is implementation intention [18], which we will outline in the following section.

\subsubsection{Implementation Intention}

Implementation Intention is a theory developed in psychology in the ' 90 s by [18]. It can be applied as a strategy to successfully achieve the planned goal.

Implementation intention is particularly suitable "when various potential routes of implementation of a given goal intention are in conflict and individuals cannot make up their mind on how to get started or what means to use" [53]. This disorientation can often be experienced by learners within MOOCs, where the orientation and success are highly dependent on her/his own level of self-efficacy and regulation.

"In order to form an implementation intention, individuals need to identify a goalrelevant situational cue (such as a good opportunity to act, or an obstacle to goal striving) and link it to an instrumental goal-directed response" [54]. Once the "cue" is identified, it needs to be detailed in the "if-then plans", "the if-component of an implementation intention specifies when and where one wants to act on this goal, and the then-component of the implementation intention specifies how this will be done" [54]. Therefore, "the basic structure of an implementation intention is as follows: IF \{ situation THEN I will \{behaviour\}", it also takes into consideration unexpected events, which are in the format of "I intend to do Y when situation $\mathrm{Z}$ is encountered" [54]. 
Implementation intention differs from goal intention, the latter is in the form: "I intend to reach Z", "goal intentions merely specify a desired future behaviour or outcome" [54], "they do not guarantee goal achievement" [55].

The effects of implementation intention on users' goal achievement have been tested and the results highlight that "when a goal intention is furnished with implementation intentions its chances of being accomplished increase. Interestingly, goal intentions that were not supplemented with implementation intentions showed rather low completion rates, suggesting that the realisation of bare goal intention is easily stifled" [53].

Implication for gamification design: enable MOOC users to make an if-plan and assess whether by allowing users to plan their intentions, it will have an impact on their goal achievement.

\subsection{Addressing Engagement}

Engagement has often been "conceptualised as the simultaneous occurrence of elevated concentration, interest, and enjoyment encapsulating the experience of flow" [56], however looking at MMOG, engagement can be connoted and experienced due to the presence of others, therefore we aim to foster engagement by valorising the social aspects of MOOC. In the following the theories of flow, social influence (persuasion) and social presence are detailed to better explain how engagement can be enhanced in MOOCs.

\subsubsection{Flow Theory}

By querying the literature, flow theory is most often cited in relation to engagement, and this is also true for gamification [57].

According to Csíkszentmihályi, flow is "a state of joy, creativity and total involvement, in which problems seem to disappear and there is an exhilarating feeling of transcendence" [19]. This "state" is achievable in types of activities that "have rules that require the learning of skills, they set up goals, they provide feedback, they make control possible. They facilitate concentration and involvement by making the activity as distinct as possible from the so-called "paramount reality" of everyday existence" [19].

Csíkszentmihályi also underlines how this pleasant state can be recreated by designing it, flow indeed has a specific set of conditions that have to be met for it to occur. These conditions require a balance of skills and challenges, clear goals, and unambiguous feedback [58]. In particular, nine components putatively facilitate the flow experience and have to be considered for its design: (f1) clear goals; (f2) focus and concentration; (f3) loss of the feeling of self-consciousness; (f4) distorted perception of time; (f5) immediate feedback; (f6) balance between challenge and skill; (f7) sense of control; (f8) intrinsically rewarding character of activity; and (f9) merging of action and awareness [59].

Implication for gamification design: enable MOOC users to reach the flow by reproducing via the MOOC content and the game elements with some of the steps detailed above.

\subsubsection{Persuasion Theory - Social Influence}

The theory of persuasion (influence) developed by Cialdini, sets out six principles, describing humans taking decisions under social influence. In our lives as well as in games and in MOOC environments people are invited to make choices. In investigating online interactions, even if the non-verbal clues are not recorded, "social category cues are still available and people may respond to influence appeals based on those cues" [8]. The theory of persuasion explains, based on the following six principles how human behaviour can be (ethically) guided in making decisions and underlines the importance of the social factor in communication [7]: (p1) social proof (consensus), (p2) liking, (p3) authority, (p4) reciprocity, (p5) scarcity, (p6) commitment and consistency.

According to this theory "the others" can be sources of persuasion and influence our behaviour. This is particularly true in case of unknown situations, where we tend to follow and observe and do what the others do ("the power of the crowd") (p1). Therefore, people 
tend to be convinced more easily by people like them (p2) (or that they like because they are attractive to them) and by people that are recognised as an authority in the field (p3). Furthermore, people tend to feel an obligation to give back if they receive something (p4), think about the coffee a colleague offers you, that receiving makes you more inclined the next time to pay for the coffee and offer one back.

A very important principle of persuasion is scarcity (p5), think about diamonds: things that are not easy to find are considered more precious than things that are widely available. This principle can also be applied to education: if, for example, a fund/grant (a title, or exam) is considered difficult to get then it is generally considered more valuable.

Finally, the last principle, according to Cialdini, commitment and consistency (p6), which imply that humans strive to avoid inconsistency in their behaviour in social situations [21]. Humans avoid that type of behaviour because it is not socially well perceived. Since "it is so typically in our best interests to be consistent, we easily fall into the habit" and automatise this behaviour [21].

These principles, in particular p5 and p6, have been studied in the context of computermediated communication (online) [44]. Results shows that "authority is successful in increasing compliance in online groups when it is used as a decision heuristic (rule of thumb), but is far less influential when present in an interactive discussion" [44]. As far as p6 is concerned, several strategies have been tested and results show that "overall it appears that the foot-in-the door effect is effective in online contexts as well as in other communication modalities" [44]

Implication for gamification design: using and applying persuasion principles we aim to engage learners by, for instance, providing game elements following the scarcity as well as commitment and consistency.

\subsubsection{Social Presence}

The term and theory of social presence were developed in the field of telecommunications by [20]. Social presence determines "the degree to which a person is perceived as a "real person" in mediated communication"[60].

Social presence varies between media and affects the way communication partners have interpersonal social interaction signalling engagement and, consequently, the establishment of interpersonal relationships. In a group, interpersonal relationships can be considered as ties between one member and another and those ties will span a space of social connections [61]. In computer(technology)-based communication the 'social space', the online environment, is the network of interpersonal relationships that exists among communicating members, which are embedded in group structures of norms and values, rules and roles, beliefs and ideals [62]. When interpersonal relationships are strong, they are a significant contributor to the effectiveness of information exchange and of influence [63] thereby reinforcing the power of persuasion. Furthermore, strong relationships may contribute to group cohesiveness and feelings of belonging. Group cohesiveness is the tendency of group members to have a sense of unity while working to achieve a shared goal and to satisfy the emotional needs of its members [64]. A feeling of belonging means that one feels connected and accepted by the other group members while giving the group members a group identity [65]. When all these qualities are found within a group, the group may experience a sense of community. Famous for this sense of community are games.

In a recent study, [46] analysed the social presence in games and the factors that make game communities thus powerful. Besides, they underlined the two factors that retain players in a specific group or guild. The first is sense of community (membership, sense of belonging) that positively impacts retention and "relation switching cost". Such a cost in online games can be described as "the losses accompanied with the breaking of the bonds that have been formed with other gamers" [46]. If the sense of community is high, the loss will be contained because the players will not afford that cost, they will stay in the same group (or guild). Furthermore, the second factor that retains players in a specific group is interdependence. "Interdependence is the degree to which members in a community rely on each other to make decisions and take actions" [46]. 
We aim to test whether by developing a sense of community and interdependence among MOOC users, their engagement will increase.

Implication for gamification design: identifying the game elements that will enable MOOC users to develop interdependency with others and a sense of community. On a more practical level, it will be important to enable users to work in small groups because collaboration and cooperation enhance interdependency.

\section{Game Elements' selection}

A literature review has been conducted with the purpose of identifying the game elements most suitable to stimulate engagement and goal achievement in an online learning scenario. As results, due to the lamented simplicity of the game elements used up to now and the scarce availability of empirical studies of gamification applied to MOOCs [23], [67], [68], we decided to query other sources, such as Björk and Holopainen's collections [69]. From this collection, 21 Game Design Patterns (GDP) ${ }^{2}$ were chosen in accordance with the following criteria (1) applicability of a GDP in a multi-user environment, and (2) correspondence with the theoretical framework presented in the previous section. The 21 $\mathrm{GDPs}^{3}$ selected were then presented to 42 experts belonging to three different but complementary backgrounds, more specifically:

(1) 17 game designers, involved because from them we expected the ability to evaluate the effects of specific GDPs in a given scenario from a game design perspective; (2) 9 learning scientists, who could judge the GDPs from a didactic and educational perspective; and (3) 16 experts in the Technology Enhanced Learning (TEL) field who could evaluate both perspectives (educational and technical) and rate the applicability and feasibility of the GDPs chosen.

Two methods were used to assess the GDPs selected: a survey and a focus group.

\subsection{Survey results (all groups involved)}

After being introduced to the concept of "MOOC" and "gamification", all participants filled in the survey designed with the aim of validating our GDP selection and collecting feedback from our target population. Using a scale from 0 ("strongly negative effects") to 4 ("strongly positive effects"), participants were asked to rate a total of 21 game elements.

The game elements proposed to our audience population were rated in accordance with a specific scenario of application (MOOC) and a given gamification purpose (gp), selectable among the following three: (gp1) enhancing users' learning performance via gamification; (gp2) enhancing users' goal achievement via gamification; (gp3) enhancing users' engagement via gamification.

Table 1 reports the GDPs that collected the highest scores, regrouped per purpose and experts' background.

\footnotetext{
${ }^{2}$ The authors are aware that "game elements" and "game design patterns" are two different concepts but here they are used as synonymous.

${ }^{3}$ The full list of the 21 GDP is available in our previous publication [67].
} 
Table 1.The GDPs ranked the highest per expert group.

\begin{tabular}{|c|c|c|c|c|c|c|}
\hline $\begin{array}{c}\text { Purpose } \\
\text { Groups }\end{array}$ & $\begin{array}{l}\text { gp1-Learning } \\
\text { performance }\end{array}$ & $x$ & $\begin{array}{c}\text { gp2-Goal } \\
\text { achievement }\end{array}$ & $x$ & $\begin{array}{c}\text { gp3-Enhancing } \\
\text { Engagement }\end{array}$ & $x$ \\
\hline \multirow{3}{*}{$\begin{array}{c}\text { Game } \\
\text { Designers }\end{array}$} & $\begin{array}{l}\text { Communication } \\
\text { Channels }\end{array}$ & 3.83 & Goal Indicators & 3.67 & $\begin{array}{c}\text { Smooth Learning } \\
\text { Curves }\end{array}$ & 4 \\
\hline & $\begin{array}{l}\text { Cooperation, } \\
\text { Replayability }\end{array}$ & \multirow{2}{*}{3.5} & Empowerment & 3.6 & $\begin{array}{l}\text { Communication } \\
\text { Channels }\end{array}$ & \multirow{2}{*}{3.8} \\
\hline & $\begin{array}{l}\text { Smooth Learning } \\
\text { Curves }\end{array}$ & & $\begin{array}{l}\text { Communication } \\
\text { Channels }\end{array}$ & 3.5 & Rewards & \\
\hline \multirow{3}{*}{$\begin{array}{l}\text { Learning } \\
\text { Scientists }\end{array}$} & Levels & 4 & $\begin{array}{c}\text { Smooth Learning } \\
\text { Curves }\end{array}$ & 4 & Storytelling & \multirow{3}{*}{4} \\
\hline & Empowerment & 3.75 & Clues & \multirow[b]{2}{*}{3.67} & Clues & \\
\hline & $\begin{array}{c}\text { Avatar, Storytelling } \\
\text { and Clues }\end{array}$ & 3.5 & Empowerment & & Empowerment & \\
\hline \multirow{3}{*}{ TEL Experts } & Levels & 3 & Goal Indicators & 4 & $\begin{array}{c}\text { Communication } \\
\text { Channels }\end{array}$ & \multirow{3}{*}{3.43} \\
\hline & $\begin{array}{l}\text { Smooth Learning } \\
\text { Curves }\end{array}$ & \multirow[b]{2}{*}{2.8} & Levels & 3.5 & $\begin{array}{l}\text { Score and Goal } \\
\text { Indicators }\end{array}$ & \\
\hline & $\begin{array}{l}\text { Storytelling and } \\
\text { Empowerment }\end{array}$ & & $\begin{array}{c}\text { Replayability and } \\
\text { Smooth Learning } \\
\text { Curves }\end{array}$ & 3.25 & $\begin{array}{c}\text { Cooperation and } \\
\text { Smooth Learning } \\
\text { Curves }\end{array}$ & \\
\hline
\end{tabular}

By analysing the quantitative data gathered from the questionnaire, it can be deduced that among the game designers a common agreement on the evaluation of expected effects of determinate game design patterns can be recorded within a MOOC for a specific purpose. More specifically, looking at the specific group evaluation: the game designers, for all three purposes, evaluated the GDP Communication Channels with a high rank. While Smooth Learning Curves was the GDP that received unanimous consensus, but it was selected for only two purposes: gp3 and gp1.

The learning scientists gave a high score to the GDP Clues, Empowerment and Storytelling, but the first received a high score for all three purposes; while the other two only for gp1 and gp2. Finally, the TEL experts' evaluation, which ranked the GDPs: Smooth Learning Curves with a high score for all three purposes; and Goal Indicators for gp2 and gp3.

Considering the similarity between the groups in ranking the GDPs, game designers and learning scientists both chose the GDP Empowerment for gp 2 and related to the p1 and p3 there is not a recorded similarity in the GDPs selected. Game designers and TEL experts agreed most in the evaluation of the GDPs. They both issued high ratings for the Smooth Learning Curves related to gp1; to Goal Indicators for gp2 e and to Communication Channels and Smooth Learning Curves for p3. While by comparing learning scientists (LS) and TEL experts, they both rated highly the GDPs: Levels, Empowerment and Storytelling for gp1. While for gp2 TEL and LS experts ranked the GDP: Smooth Learning Curves the highest. As for gp3 there is no agreement among the three groups, therefore no common GDPs with a high score.

\subsection{Focus Group highlights}

The focus group was delivered before the survey and dedicated only to game designers. This was done with the aim of inviting them to conceptualise a gamified MOOC using the game elements that they deemed most relevant.

Each group of game designers was invited to conceptualise the design of a gamified MOOC using, based on their experience, the most suitable game elements to gamify it in order to enhance users' learning performance (gp1); goal achievement (gp2) or engagement (gp3). Each purpose was chosen, autonomously, by two of the six groups, respectively. The topic of the MOOC was given as cyber-security. Each group elaborated a presentation that was presented to the other game designers. 
The first two groups conceptualised the gamification design on the gp1: enhancing learning performance, and they identified the following game elements: Group 1 proposed using collaboration via wiki and forum, aiming at developing a sense of community and information sharing, track of personal progress, levels and different complexity of tasks, with a rewarding system for their completion and an inventory for personal notes, in which to save helpful posts from the community forum. They also thought of implementing a game itself within the MOOC. Group 2 proposed aiming at allowing users to follow an autonomous path, as well as a collaborative path, that could be enabled by the creation of alliance, asymmetrical information distribution for the solution of boss tests. In addition, group 2 suggested including several levels within the MOOC and a skill tree $e^{4}$ which is a game element often present in roleplaying games, (the Diablo ${ }^{5}$ series made it famous) and it enables custom configurations of a character's abilities.

Group 3 and 4 conceptualise on a gamification design for MOOCs aiming at enhancing goal achievement (gp2). Group 3 proposed "personal profiles that can be shared with others, badges as rewards, progress bar and autonomy". Group 4 came up with the following idea of transferring the MMOG elements into MOOC, such as: skill tree, connected with learning needs, learning content and tasks, with a test after each MOOC; "knowledge inventory (completed tasks for the course); overview (whole offer, progress per Skill tree); Co-op (Cooperation with "Classes"); PVP (Player vs. Player "Knowledge Battle"); reward inside system (skill tree, knowledge inventory, successful students as mentors for newbies); reward outside systems (achievements, link to LinkedIn)".

The last two groups $(5,6)$ of game designers worked on the conceptualisation of a gamified MOOC for gp3 (engagement). Group 5 proposed the use of competition, collaboration and immediate feedback as game elements to enhance users' engagement. They suggested integrating a game concept similar to QuizClash in a MOOC platform: an online quiz game for two players, where one player chooses from several categories and challenges a friend. Both receive the same question and the one who replies faster and correctly wins. The game element was chosen because activating social comparison could engage students. Group 6 proposed using the following game elements to enhance users' engagement in MOOCs: quests, narrative, player/character, enemy/boss, community (guild)/community experience and status parameter. In particular, the narrative conceptualised consists of "some sort of opposing power that threatens the participants' characters and their private information". In this framework, the participant's goal is to work against this power to protect his/her own identity. The players will work together cooperatively against the system and develop a resistance force. As one of the participants states: "The player needs to use what s/he learns in the modules of the course to contribute to the success of this resistance". Being part of this resistance could help in developing "a sense of community similar to MMORPG (Massive Multiplayer-Online Role Play Games) communities such as guilds". "Even if participants are working alone, they should feel that they are contributing to the cause of the resistance/the community", therefore collaboration has to be an option and "it will not be enforced".

On the basis of our framework and the qualitative and quantitative data collected, the GDPs eligible for our implementation are (1) Empowerment, (2) Smooth Learning Curves (3), Communication Channels, (4) Levels, (5) Clues, (6) Goal Indicators, (7) Skill tree; (8)

\footnotetext{
${ }^{4}$ It is called a tree because once the basic skills are gained by the users, it opens several branches and the user can decide what to follow

${ }^{5}$ Blizzard production, 1998. http://eu.blizzard.com/en-gb/games/
} 
page 72

Guild and (9) Storytelling and (10) Stimulated Planning in the next paragraph we map these with our theoretical framework to give readers a better overview of their design.

\section{Towards game elements design and implementation}

Based on the study presented and our theoretical framework and considerations, the ten game elements, mentioned above, were selected and here the connection with our theories is further pointed out.

More specifically, for each game element a brief description, the links (if any) with the nine, flow components (f1-f9); the six persuasion principles (p1-p6), social persuasion and implementation intention theories are presented.

(g1) Empowerment ("Players feel that they can affect the events and the final outcome of a game"[69]) and this delivers a sense of control (f7) to learners. Empowerment also helps to foster the intrinsically rewarding character of actions (f8) by supporting selfefficacy, as well as being able to support the loss of feeling of self-consciousness (f3) by involving the user in the action itself. Commitment and consistency (p1) are supported since empowerment leads to individual decisions the learner commits to and to consistent actionresponse cycles. On an individual level, implementation intention can generate this feeling and support this game element. In the act of taking decisions and planning learners are empowered. It can also play an important role on a social level if group decision and action are enabled.

(g2) Smooth Learning Curves (enable the chance to "smoothly progress from novice to master" [69]) help to gain focus and concentration (f2) as well as a balance between challenge and skills (f6), as they avoid overly complex or too simple learning situations. This game element also supports commitment and consistency (p1) by designing the learning progress in a consistent way. It can be stimulated by the intervention of the other enabling users to develop a sense of belonging and community (social presence). Within a MOOC scenario, this game element can be implemented by structuring the content from the easiest to the most difficult, using the levels functionality available in some of the platforms on the market. As well as being possible by differentiating the content that users see.

(g3) Communication Channels ("the medium and the methods players can use to send messages to other players" [69]) enable clear and immediate feedback (f5) from peers and tutors, but also support reciprocation (p2) by allowing learners to communicate and exchange knowledge/information/favours. Social proof (p3) can be supported by communication channels as well, since the behaviour of community members can be part of the communication. By communicating interdependence and sense of community can be developed, as a matter of fact, if there is no communication (synchronous or asynchronous) the social presence cannot be perceived. In several MOOC platforms forums are available, and in some external plugins can be integrated.

(g4) Levels ("part of the game in which all players' actions take place until a certain goal has been reached or an end condition has been fulfilled"[69]) can be used to support a balance between challenge and skill (f6), since they complement the smooth learning curve with a game design approach to design increasing challenges. Levels also support consistency and commitment (p1), by representing closed, consistent environments, which the learner commits to finishing. The design of different levels can also provide scarcity (p6) by using various level elements in varying frequency. Levels can be used to foster interdependency and help users to develop a sense and community.

(g5) Clues ("game elements that give the players information about how the goals of the game can be reached" [69]), this game element that can be used in a large variety of different ways. Consequently, clues can be used to indicate clear goals (f1), to help focusing and concentration (f2) by directing the learner to relevant aspects, to help dissolve a distorted perception of time (f4) by pointing towards breaks or session ends, to give clear and immediate feedback (f5), and to support the balance between challenge and skills (f6), 
by guiding a lost learner towards solutions. Clues can also underline consistency (p1) by directing the learner's attention or represent authority (p4) by giving direction. Clues can be given to enable a user perceiving the other's presence. For instance, a notification can be given to a user when another is busy with the same activity, and or has finished it. Clues should be realised using principles of scarcity (p6).

(g6) Goal Indicators (give information to players about their current goals in the game), help to indicate, set, and follow clear goals (f1). Goal indicators also support commitment (by fostering goal achievement) and consistency (by allowing for long-term oriented goals) (p1). When goal indicators are used to guide the learner, they can also represent authority (p4). Furthermore, the achievement of a specific goal can be intrinsically rewarding for the learner (f8). Goal Indicators can also be set for group activities to help users to develop interdependency and sense of community.

(g7) Skill trees (enable custom configurations of a character's abilities, often organised in branches) support the design of balanced challenges and skills (f6) and as levels support consistency and commitment (p1). This fosters user engagement more on an individual level.

(g8) Guilds ("associations of players who choose to come together to achieve a common goal" [70], [71] can be used to streamline clear goals (f1) and foster communication and collaboration, which helps to support reciprocation $(\mathrm{p} 2)$, social proof (p3), linking (p5), as well as authority (p4). Guild is a very important game element to develop interdependency with other learners and the sense of belonging from that specific community of people, therefore guilds are more related to the social dimension of MOOCs.

(g9) Storytelling ("the act of telling stories within the game" [69]) can be flexibly used for many contextualising or framing objectives. It offers opportunities to foster focusing and concentration (p2) by providing an interesting story line. It can support the loss of feeling of self-consciousness (f3) by immersing the learner in the story. When storyline and user activities are well integrated, storytelling can support the merging of action and awareness (f9).

(g10) Stimulated Planning ("It encourages players to plan certain aspects of the game" [69]) and by doing so enables users to feel empowered (f7) and to choose freely. Furthermore, this action of planning fosters a cognitive work (f2) and immersion that can possibly bring users to lose a sense of time (f4). It is a game element that can help users create their if-plan and achieve their planned goal, as postulated by the implementation intention theory.

\section{How to embrace the individual and social aspects in designing gamification of MOOCs}

The social and individual aspects of MOOCs are both reflected in our gamification design of MOOCs, more specifically in the problems identified (goal achievement- individual and engagement- social), the theories we refer to (individual: flow and implementation intention; social: persuasion and social presence), the game elements selected and described in the overview above. In valorising these two aspects we have underlined the importance of also taking into consideration the other peculiarities of our application scenario (openness, course design, technology). See Figure 3, below 


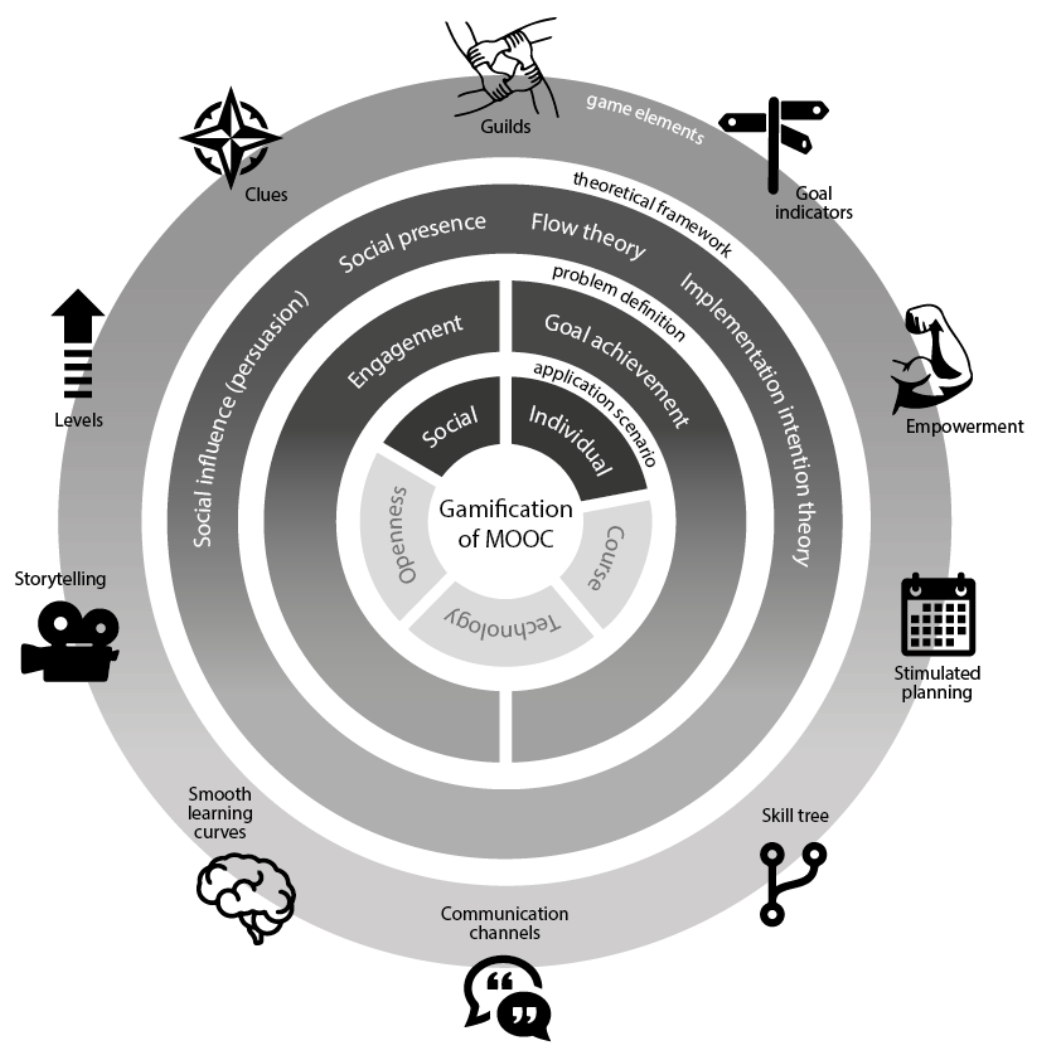

Figure 3. Gamification of MOOC embracing the individual and social aspects of $\mathrm{MOOCs}$

In our design approach the individual and social aspects are brought together. On the one hand, our gamification design aims at enabling individuals (learners) to achieve their own goals by fostering the action of detailing their if-plan (implementation intention theory - game element: stimulated planning). On the other hand, by valorising the social aspect with our design we aim at creating a sense of community among MOOC users that will increase their engagement (social presence theory - game elements, mainly: guilds, communication channels, levels, clues, goals indicators). However, as gathered from our theories the social and individual aspects do not have tight boundaries; there are some grey areas.

These grey areas, can be found, in particular in our theories of reference, as represented in the figure 3, there are not divisor between the individual and social side. Considering for instance flow theory, flow per se can be seen not only within individual activities, but it also has some social component. Think about working together with other people on a project or conduct a mission on Halo, it can happen that group are in the flow by doing something together. The same logic can be applied to the social side, social influence and persuasion as well are relative to individual observation and are strictly related to how the person codifies that reality. In this sense, self-efficacy is a very important mediator for all the theories embedded in our framework [72]-[74] (and is considered in our evaluation strategy), if a person doesn't feel confident enough is very likely that his/her own judgment is biased. Furthermore, looking at gamification in general, what we try to stress is that individual and social aspects of the gamification of MOOCs represent two different sides of the same coin, part of the same phenomenon that influence each other. Treating them as separate would be a mistake in design.

As a conclusion, this study contributes to the field by presenting MOOCs under another light (social and individual aspects together) along with the gamification design. After presenting the relative characteristics of the gamification design, we introduced our 
gamification design cycle, which is designed to be context independent and which can be used as a generic baseline to approach the design of gamification in several scenarios of application. We have applied it to MOOC, each phase has been described and detailed in relation to the application scenario.

In selecting the game elements, we have decided to use a resource that has been tested to be effective in the field of serious games (SG) [75] and mobile SG [76], which is the collection of GDP from Björk and Holopainen [69], not yet used to design gamification of MOOC. In this way we have contributed to the field by presenting new game elements within MOOCs, such as stimulated planning, which is often used in strategy games. Besides, we have identified (by investigating the literature) two core mechanisms that engage players in MMOG and found game elements that could generate interdependency and sense of community within MOOCs.

The conceptual design of the game elements selected has been linked with our theoretical framework and the aim we want to address in MOOC (goal achievement and engagement of users).

By describing our theoretical framework, we have borrowed two theories new to gamification from two different fields: (1) implementation intentions, which has been applied successfully in health psychology and (2) social influence, persuasion, massively and fruitfully applied in marketing to try to underline how the theories are important in selecting the game elements and can orient the design of these.

The next step will be the evaluation ( $6^{\text {th }}$ phase of the gamification design cycle). Performing phase six- evaluation implies implementing the game elements in a MOOC platform (Open edX) and conducting formative and summative studies to understand whether our gamification design solves the problem we aim to address and the effect of our game elements

As future work we aim to validate the effectiveness of the gamification design cycle in contexts different from MOOC, such as a traditional university class/course, and apply it in non-educational contexts too.

\section{References}

[1] Meschede, C. and Knautz, K., "Gamification and Interdisciplinarity: Challenges in the Modern Knowledge Society," Int. J. Inf. Commun. Technol. Hum. Dev., vol. 9, no. 3, pp. 1-13, 2017. https://doi.org/10.4018/IJICTHD.2017070101

[2] Deterding, S., Dixon, D, Khaled, R., \& Nacke, L., "From Game Design Elements to Gamefulness: Defining 'Gamification,"' Proc. 2011 Annu. Conf. Ext. Abstr. Hum. factors Comput. Syst. - CHI EA '11, p. 2425, 2011.

[3] Mora, A., Riera, D., Gonzalez, C., \& Arnedo-Moreno, J., "A Literature Review of Gamification Design Frameworks," in VS-Games 2015 - 7th International Conference on Games and Virtual Worlds for Serious Applications, 2015.

[4] Calderón, A., Boubeta-Puig, J., \& Ruiz, M., "MEdit4CEP-Gam: A model-driven approach for user-friendly gamification design, monitoring and code generation in CEP-based systems," Inf. Softw. Technol., vol. 95, pp. 238-264, Mar. 2018. https://doi.org/10.1016/j.infsof.2017.11.009

[5] Morschheuser, B., Hassan, L., Werder, K., \& Hamari, J., "How to design gamification? A method for engineering gamified software," Inf. Softw. Technol., vol. 95, pp. 219-237, Mar. 2018. https://doi.org/10.1016/j.infsof.2017.10.015

[6] García, F., Pedreira, O., Piattini, M., Cerdeira-Pena, A., \& Penabad, M., "A framework for gamification in software engineering," J. Syst. Softw., vol. 132, pp. 21-40, Oct. 2017. https://doi.org/10.1016/j.jss.2017.06.021

[7] Brito, J., Vieira, V., \& Duran, A., "Towards a Framework for Gamification Design on Crowdsourcing Systems: The G.A.M.E. Approach," 2015 12th Int. Conf. Inf. Technol. - New Gener., pp. 445-450, 2015.

[8] Advancement courses, "The Engineering Design Process: The 4 Key Steps to STEM Teaching and Learning - Advancement Courses." [Online]. Available: 
page 76

https://www.advancementcourses.com/blog/the-engineering-design-process-the-4-key-stepsto-stem-teaching-and-learning/. [Accessed: 05-Sep-2018].

[9] Olsson, M., Mozelius, P., and Collin, J., "Visualisation and gamification of e-Learning and programming education," Electron. J. e-Learning, vol. 13, no. 6, pp. 441-454, 2015.

[10] Mazarakis, A., "Using Gamification for Technology Enhanced Learning : The Case of Feedback Mechanisms," Bull. IEEE Tech. Comm. Learn. Technol., vol. 17, no. 4, pp. 6-9, 2015.

[11] Pedreira, O, García, F., Brisaboa, N., \& Piattini, M., "Gamification in software engineering - A systematic mapping," Inf. Softw. Technol., vol. 57, no. 1, pp. 157-168, 2015. https://doi.org/10.1016/j.infsof.2014.08.007

[12] Insley V., and Nunan, D., "Gamification and the online retail experience," Int. J. Retail Distrib. Manag., vol. 42, no. 5, pp. 340-351, 2014. https://doi.org/10.1108/IJRDM-01-2013-0030

[13] Lucassen, G., Jansen, S., "Gamification in Consumer Marketing - Future or Fallacy?," Procedia - Soc. Behav. Sci., vol. 148, pp. 194-202, 2014.https://doi.org/10.1016/j.sbspro.2014.07.034

[14] Kappen, D. L., Mirza-Babaei, P., \& Nacke, L. E., "Gamification through the Application of Motivational Affordances for Physical Activity Technology," Proc. Annu. Symp. Comput. Interact. Play - CHI Play '17, pp. 5-18, 2017.

[15] Creswell, J. W., Educational Research. Planning, Conducting and Evaluation Quantitative and Qualitative Research, 4th Editio. Pearson, 2002.

[16] Lederman, N. G., Lederman, J. S., "What Is A Theoretical Framework? A Practical Answer," J. Sci. Teacher Educ., vol. 26, no. 7, pp. 593-597, Dec. 2015. https://doi.org/10.1007/s10972-0159443-2

[17] Seaborn, K., Fels, D. I., "Gamification in theory and action: A survey," Int. J. Hum. Comput. Stud., vol. 74, pp. 14-31, 2014. https://doi.org/10.1016/j.ijhcs.2014.09.006

[18] Gollwitzer, P. M., "Implementation intentions," Am. Psychol., vol. 54, no. 7, pp. 493-503, 1999. https://doi.org/10.1037/0003-066X.54.7.493

[19] Csikszentmihalyi, M., Flow: the psychology of happiness. Rider, 1992.

[20] Short, J., Williams, E., \& Christie, B., The Social Psychology of Telecommunications, vol. 7, no. 1. London: John Wiley \& Sons, 1976.

[21] Cialdini, R. B., Influence: The Psychology of Persuasion, Revised Ed. HarperCollins e-books, 2001.

[22] Webb, E. N., "Gamification: When it works, when it doesn't," Lect. Notes Comput. Sci. (including Subser. Lect. Notes Artif. Intell. Lect. Notes Bioinformatics), vol. 8013 LNCS, no. PART 2, pp. 608-614, 2013.

[23] Gené, O. B., Mart, M., \& Blanco, Á. F, "Gamification in MOOC: Challenges, Opportunities and Proposals for Advancing MOOC Model," in Proceedings of the 2nd International Conference on Technological Ecosystems for Enhancing Multiculturality, 2014, pp. 215-220.

[24] Borras-Gene, O., Martinez-Nunez, M., \& Fidalgo-Blanco, A., "New Challenges for the Motivation and Learning in Engineering Education Using Gamification in MOOC," Int. J. Eng. Educ., vol. 32, no. 1(B), pp. 501-512, 2016.

[25] Chauhan, J., Taneja, S., \& Goel, A., "Enhancing MOOC with Augmented Reality, Adaptive Learning and Gamification," in 2015 IEEE 3rd International Conference on MOOCs, Innovation and Technology in Education (MITE), 2015, pp. 348-353.

[26] Khalil, M., Ebner, M., \& Admiraal, W., "How can Gamification Improve MOOC Student Engagement?"

[27] Zhu, Y., Pei, L., \& Shang, J., "Improving Video Engagement by Gamification: A Proposed Design of MOOC Videos," in Blended Learning. New Challenges and Innovative Practices. ICBL 2017. Lecture Notes in Computer Science, 2017, pp. 433-444. https://doi.org/10.1007/978-3-319-59360-9 38

[28] Bjork S., Holopainen, J., Patterns in Game Design (Game Development Series), 1st ed., vol. 54. Charles River Media, 2004.

[29] Morales, M., Amado-Salvatierra, H. R., Hernández, R., Pirker, J., \& Gütl, C., "A Practical Experience on the Use of Gamification in MOOC Courses as a Strategy to Increase Motivation," in Learning Technology for Education in Cloud - The Changing Face of Education. LTEC 2016.Communications in Computer and Information Science, 2016, vol. 620, pp. 139-149. https://doi.org/10.1007/978-3-319-42147-6_12

[30] Landers, R. N., Landers, A. K., "An empirical test of the theory of gamified learning: The effect of leaderboards on time-on-task and academic performance," Simul. Gaming, vol. 45, no. 6, pp. 769-785, 2014. https://doi.org/10.1177/1046878114563662 
[31] Kyewski, E., Krämer, N. C., "To gamify or not to gamify? An experimental field study of the influence of badges on motivation, activity, and performance in an online learning course," Comput. Educ., vol. 118, no. November 2017, pp. 25-37, 2018.

[32] Christy, K. R., Fox, J., "Leaderboards in a virtual classroom: A test of stereotype threat and social comparison explanations for women's math performance," Comput. Educ., vol. 78, pp. 66-77, 2014. https://doi.org/10.1016/j.compedu.2014.05.005

[33] Saraguro-Bravo, R. A., Jara-Roa, D. I. \& Agila-Palacios, M., "Techno-instructional application in a MOOC designed with gamification techniques," in 2016 3rd International Conference on eDemocracy and eGovernment, ICEDEG 2016, 2016, pp. 176-179.

[34] Staubitz, T., Willems, C., Hagedorn, C., \& Meinel, C., "The gamification of a MOOC platform," in Global Engineering Education Conference (EDUCON), 2017, no. January, pp. 883-892.

[35] Mesquita, M. A. A., Toda, A. M., \& Brancher, J. D., "BrasilEduca - An Open-Source MOOC platform for Portuguese speakers with gamification concepts," IEEE Front. Educ. Conf., pp. 446-449, 2014.

[36] Vaibhav, A., Gupta, P., "Gamification of MOOCs for increasing user engagement," Proc. 2014 IEEE Int. Conf. MOOCs, Innov. Technol. Educ. IEEE MITE 2014, pp. 290-295, 2014.

[37] Bakar, N. F. A., Yusof, A. F., Iahad, N. A., \& Ahmad, N., "The Implementation of Gamification in Massive Open Online Courses (MOOC) Platform," in User Science and Engineering. i-USEr 2018. Communications in Computer and Information Science, vol 886, 2018, pp. 183-193.

[38] Aparicio, M., Oliveira, T., Bacao, F., \& Painho, M., "Gamification: A key determinant of massive open online course (MOOC) success," Inf. Manag., Jun. 2018 https://doi.org/10.1016/j.im.2018.06.003

[39] Drachsler, H., Kirschner, P. A., "Learner Characteristics," Encyclopedia of the Sciences of Learning, vol. 4. Springer, pp. 1743-1745, 2012.

[40] Vygotsky, L. S., Mind in society: The development of higher psychological processes. Cambridge, Massachusetts: Harvard University Press, 1980.

[41] Bandura, A., "Social cognitive theory: An agentic perspective," Annu. Rev. Psychol., vol. 52, no. 1, pp. 1-26, 2001.https://doi.org/10.1146/annurev.psych.52.1.1

[42] Festinger, L., "A Theory of Social Comparison Processes," Hum. Relations, vol. 7, no. 2, pp. 117-140, May 1954. https://doi.org/10.1177/001872675400700202

[43] Guadagno, R. E., Cialdini, R. B., "Online Persuasion and Compliance: Social Influence on the Internet and Beyond," in The Social Net: The Social Psychology of the Internet, The social., no. APRIL 2009, Y. Amichai-Hamburger, Ed. Oxford, UK: Oxford University Press, 2005, pp. 91113.

[44] Kankanhalli, Y. Wu, A., Huang, K.,"Gamification in Fitness Apps: How Do Leaderboards Influence Exercise?," in Icis, 2015, pp. 1-12.

[45] Tseng, F. C., Huang, H. C., \& Teng, C. I.,"How Do Online Game Communities Retain Gamers? Social Presence and Social Capital Perspectives," J. Comput. Commun., vol. 20, no. 6, pp. 601614, 2015.

[46] Lowenthal, P. R., The Evolution and Influence of Social Presence Theory on Online Learning, no. May. 2009.

[47] Margaryan, A., Bianco, M. \& Littlejohn, A., "Instructional Quality of Massive Open Online Courses (MOOCs)," Comput. Educ., vol. 80, pp. 77-83, 2015. https://doi.org/10.1016/j.compedu.2014.08.005

[48] Antonaci, A, Klemke, R., Stracke, C. M., \& Specht, M., "Gamification in MOOCs to enhance users' goal achievement," in IEEE Global Engineering Education Conference, EDUCON, 2017.

[49] Kalz, M., Specht, M., "If MOOCS are the answer, did we ask the right questions? Implications for the design of large-scale online-courses," Maastricht School of Management, Maastricht, The Netherlands, 2013.

[50] Landers, R. N., Landers, A. K., "An Empirical Test of the Theory of Gamified Learning: The Effect of Leaderboards on Time-on-Task and Academic Performance," Simul. Gaming, vol. 45, no. 6, pp. 769-785, 2014. https://doi.org/10.1177/1046878114563662

[51] Aparicio, A., Vela, F., "Analysis and application of gamification," in Proceedings of the 13th International Conference on Interaccion Persona-Ordenador, 2012.

[52] Gollwitzer, P. M., "Goal Achievement: The Role of Intentions," Eur. Rev. Soc. Psychol., vol. 4, no. 1, pp. 141-185, Jan. 1993. https://doi.org/10.1080/14792779343000059

[53] Gollwitzer P. M., Oettingen, G., "Implementation Intentions," in Encyclopedia of Behavioral Medicine, T. J.R., Ed. New York, NY: Springer New York, 2013, pp. 1043-1048. 
[54] Gollwitzer P. M., Sheeran, P., "Implementation intentions and goal achievement: A metaanalysis of effects and processes," Adv. Exp. Soc. Psychol., vol. 38, pp. 69-119, 2006. https://doi.org/10.1016/S0065-2601(06)38002-1

[55] Hamari, J., Shernoff, D. J, Rowe, E., Coller, B., Asbell-Clarke, J. \& Edwards, T., "Challenging games help students learn: An empirical study on engagement, flow and immersion in gamebased learning," Comput. Human Behav., vol. 54, pp. 170-179, 2016. https://doi.org/10.1016/j.chb.2015.07.045

[56] Hamari, J., Koivisto, J., "Measuring flow in gamification: Dispositional Flow Scale-2," Comput. Human Behav., vol. 40, pp. 133-143, 2014. https://doi.org/10.1016/j.chb.2014.07.048

[57] Csikszentmihalyi, M., Finding flow : the psychology of engagement with everyday life.

[58] Csikszentmihalyi, M., Csikszentmihalyi, I. S., Optimal experience : psychological studies of flow in consciousness. Cambridge University Press, 1988. https://doi.org/10.1017/CBO9780511621956

[59] Gunawardena C. N., Zittle, F. J., "Social presence as a predictor of satisfaction within a computer-mediated conferencing environment," Am. J. Distance Educ., vol. 11, no. 3, pp. 8-26, 1997. https://doi.org/10.1080/08923649709526970

[60] Katz, N., Lazer, D., Arrow, H., \& Contractor, N., "Network Theory and Small Groups," Small Gr. Res., vol. 35, no. 3, pp. 307-332, Jun. 2004. https://doi.org/10.1177/1046496404264941

[61] Kreijns, K., Van Acker, F., Vermeulen, M., \& Van Buuren, H.,"Community of Inquiry: Social Presence Revisited," E-Learning Digit. Media, vol. 11, no. 1, pp. 5-18, Feb. 2014. https://doi.org/10.2304/elea.2014.11.1.5

[62] Warkentin, M. E., Sayeed, L., \& Hightower, R., "Virtual Teams versus Face-to-Face Teams: An Exploratory Study of a Web-based Conference System," Decis. Sci., vol. 28, no. 4, pp. 975996, Oct. 1997. https://doi.org/10.1111/j.1540-5915.1997.tb01338.x

[63] Carron, A. V., Brawley, L. R., "Cohesion. Conceptual and Measurement Issues," Small Gr. Res., vol. 31, no. 1, pp. 89-106, Feb. 2000. https://doi.org/10.1177/104649640003100105

[64] Osterman, K. F., "Students' Need for Belonging in the School Community," Rev. Educ. Res., Jun. 2000. https://doi.org/10.3102/00346543070003323

[65] Parks, M. R., Floyd, K., "Making Friends in Cyberspace," J. Comput. Commun., vol. 1, no. 4, Mar. 1996.

[66] Antonaci, A., Klemke, R., Stracke, C. M., \& Specht, M., "The Effects of Gamification in Online Learning Environments: A Systematic Literature Review," Comput. Hum. Bahavior, 2018.

[67] Björk S., Holopainen, J., Patterns in Game Design. 2005.

[68] Riegle R. P., Matejka, W. A., "The learning guild: MMORPGs as educational environments," in 22nd Annual Conference on Distance Teaching and Learning, 2006.

[69] Knautz, K., Göretz, J. \& Wintermeyer, A., "'Gotta Catch 'Em All' - Game Design Patterns for Guild Quests in Higher Education," in iConference 2014 Proceedings, 2014, pp. 690-699 .

[70] Webb, T. L., Sheeran, P., "Mechanisms of implementation intention effects: The role of [1] Meschede, C. and Knautz, K., "Gamification and Interdisciplinarity: Challenges in the Modern Knowledge Society," Int. J. Inf. Commun. Technol. Hum. Dev., vol. 9, no. 3, pp. 1-13, 2017

[71] Webb, T. L., Sheeran, P., "Mechanisms of implementation intention effects: The role of goal intentions, self-efficacy, and accessibility of plan components," Br. J. Soc. Psychol., vol. 47, no. 3, pp. 373-395, 2008. https://doi.org/10.1348/014466607X267010 1111

[72] Wrench, J. S., Punyanunt-Carter, N. M., "The Relationship between Computer-MediatedCommunication Competence, Apprehension, Self-Efficacy, Perceived Confidence, and Social Presence," South. Commun. J., vol. 72, no. 4, pp. 355-378, Nov. 2007. https://doi.org/10.1080/10417940701667696

[73] Lucas, T., Alexander, S., Firestone, I. J., \& Baltes, B. B., "Self-efficacy and independence from social influence: Discovery of an efficacy-difficulty effect," Soc. Influ., vol. 1, no. 1, pp. 5880, Mar. 2006. https://doi.org/10.1080/15534510500291662

[74] Kelle, S., Klemke, R., \& Specht, M., "Design patterns for learning games," Int. J. Technol. Enhanc. Learn., vol. 3, no. 6, pp. 555-569, 2011. https://doi.org/10.1504/IJTEL.2011.045452

[75] Schmitz, B., Klemke, R., \& Specht, M., "Mobile gaming patterns and their impact on learning outcomes: A literature review," in 21st Century Learning for 21st Century Skills - Proceedings of the 7th European Conference of Technology Enhanced Learning, EC-TEL 2012, Lecture Notes in Computer Science, 2012, vol. 7563, pp. 1-6. 